\title{
JUAN RADRIGÁN E PLÍNIO MARCOS: CONTEXTOS E TEXTOS DRAMÁTICOS/ESPETACULARES
}

Marcos Antônio Alexandre*

RESUMO:

\begin{abstract}
Este ensaio tem como objetivo realizar um breve estudo comparativo entre a obra dramática e espetacular do dramaturgo chileno Juan Radrigán (1937) e do dramaturgo brasileiro Plínio Marcos (1936/1999). A partir desse estudo, busca-se entender melhor as particularidades da história política brasileira e chilena, uma vez que ambos os dramaturgos conceberam grande parte de suas obras dramáticas sob o período ditatorial em seus respectivos países.

PALAVRAS-CHAVE: Juan Radrigân, Plinio Marcos, contextos, textos dramáticos, textos espetaculares.
\end{abstract}

Juan Radrigán e Plínio Marcos sempre declararam que, através de seus textos teatrais, eles tinham a oportunidade de fazer do "povo comum", o elemento primordial de suas dramaturgias. Dar voz ao marginalizado tornou-se, assim, o viés norteador da grande maioria das obras dos dois dramaturgos, fazendo do cunho social uma ferramenta não só para resgatar, mas também para reconhecer e questionar a situação em que vivem os marginalizados nas suas respectivas sociedades. Por esse motivo, a análise comparativa das peças plinianas e radriganeanas permite-nos que compreendamos seus contextos específicos de enunciação e de inserção cultural, possibilitando o reconhecimento e o melhor entendimento de momentos históricos fundamentais na construção e reconstrução da vida político-social das nações chilena e brasileira no século XX e na nossa contemporaneidade. Como Bhabha (1988:34), considero que "o crítico deve tentar apreender totalmente e assumir a responsabilidade pelos passados não ditos, não representados, que assombram o presente histórico".

| Doutor em Letras: Literatura e outros Sistemas Semióticos (Área de concentração: Literatura Comparada), 2004 


\section{EMTESE}

Belo Horizonte, v. 9, p. I-28I, dez. 2005

Com base nesses dizeres, pesquisar as obras plinianas e radriganeanas possibilitanos, a partir de suas dramaturgias estabelecer um diálogo entre a história dos dois países, fazendo com que possamos de fato resgatar os passados não ditos.

Juan Radrigán é qualificado pelo crítico Grínor Rojo como "o grande investigador do teatro chileno desde 1979 até 1982". 0 dramaturgo colocou em pauta, no cenário, a situação limite de seres que sofrem, sentem e pensam, através de uma dramaturgia em que o sentimentalismo dá lugar à ternura e de onde, mesmo a partir das circunstâncias mais dolorosas, é capaz de brotar a solidariedade. Daí, a força que emana de suas tramas e argumentos que conseguem causar impacto e convencer "fazer-crer" nos dizeres de Marco De Marinis (1997) - sem fazer uso de recursos que não sejam nada mais do que a retratação da verdade simples, da realidade. Alguns jornalistas de teatro criticaram Radrigán pelo fato de suas personagens "parecerem ter sido retiradas das cloacas sociais" ou pela posição moralizante diante da desolação humana, da pobreza, da miséria moral e também pela sensação de angústia produzida pelos diálogos de suas personagens. Entretanto, o autor sempre defendeu seu teatro de reflexão crítica, expondo que tinha começado a escrever "em pleno inferno e nada tinha mudado, o quadro de horror mantém-se inalterável. Somos um povo que não se deu tempo para chorar pelos seus mortos, que não incorporou a suas entranhas a brutal derrota sofrida. Decididamente, é um material não apto para as comédias". A partir dessas palavras, posso afirmar que a aproximação do dramaturgo ao teatro esteve impulsionada pela necessidade de "comunicar", ou seja, Radrigán sentia a urgência de chegar mais rápido ao público e ponderou que o teatro seria o caminho mais direto.

Plínio Marcos apresenta uma biografia que se relaciona muito com a de Radrigán. Nascido em Santos em 1935, o autor abandonou, ainda adolescente, os estudos formais concluindo apenas o curso primário. Profissionalmente, também ocupou várias funções. Como Radrigán, Plínio sempre fez do cidadão comum o objeto principal de sua dramaturgia. Foi a curra sofrida na cadeia por um garoto conhecido, que o levou a escrever Barrela (1959-1980) aos vinte dois anos de idade e, a partir desse momento, ele não abandonou a escrita e as personagens marginais e marginalizadas que o consagraram. Essas personagens, representadas sob diferentes abordagens críticas e semânticas, sempre povoaram seus textos que, constantemente, converteram- 
se em motivo de polêmicas e proibições por parte da censura. Segundo Javier Arancibia Contreras, Fred Maia e Vinícius Pinheiro (2002:12),

Em Plínio Marcos, o dramático é um ato espontâneo. Nasce da aguda naturalidade (e mesmo do naturalismo) com que desenha as frases, engendra a ação verbal, grava o pormenor que não poderia possuir outro talhe. Isso advém, quero crer, do mesmo modo como o autor enxergava a vida e vivia os fatos que ela propiciava: pelos olhos e com a sensibilidade de quem está inteiramente na situação, sem mediações, exposto à curiosidade pública como o cru latejamento de um músculo lanhado.

Grande parte da dramaturgia de Juan Radrigán e Plínio Marcos foi escrita e concretizada num contexto histórico específico - o autoritarismo. Em ambos os países a dimensão do regime ditatorial foi devastadora: prisões, torturas, cassação de direitos civis, assassinatos, censuras, traumas, ausência e aniquilamento da memória. Talvez, a diferença mais relevante seja o fato de que a ditadura chilena esteve sobre o jugo de um único homem, o general Augusto Pinochet. Segundo Idelber Avelar (2003), a dimensão e o impacto do exílio na cultura chilena foi muito maior do que no Brasil. Radrigán disse em entrevista a mim concedida, em 2001 - que, em relação à classe artística, houve repressão, porém não se pôde proibir que as pessoas pensassem. Entretanto, o que deve ser enfatizado é que o horror da repressão foi vivido nos dois países e é pelo exposto que sustento a idéia de que não há como analisar as obras dramáticas desses autores sem o entendimento dos regimes de opressão aos quais estiveram submetidos os cidadãos chilenos e brasileiros e sem concretizálas ao nosso contexto de enunciação. Nesse sentido, o conceito de "historicizar" proposto por Juan Villegas (1998), assume um caráter fundamental para a análise das obras plinianas e radriganeanas. Segundo o autor, numa de suas acepções,

Historizar también significa entender al autor como productor de significados. Es decir, conceder importancia al autor en cuanto un individuo frente al mundo, frente a su circunstancia y cuya respuesta no constituye una respuesta individual sino una respuesta colectiva, desde la perspectiva de un determinado modelo de mundo producto de una ideología. (Villegas, 1998: 53)

Na minha leitura, tanto Radrigán quanto Plínio Marcos, cada um dentro de suas especificidades e a partir de seus contextos sócio-culturais, são produtores de sentidos, uma vez que seus textos nos fazem repensar os seus momentos de 


\section{EMTESE}

Belo Horizonte, v. 9, p. I-28I, dez. 2005

inscrição, possibilitando que realizemos um diálogo dos mesmos com o nosso momento enunciador. Dessa forma, estudar o periodo da ditadura brasileira e chilena e contextualizá-10 a partir das obras de Plínio Marcos e Radrigán permite não apenas conhecer, mas também entender melhor o porquê de se retratar as personagens marginalizadas e os motivos pelos quais elas se fizeram centro da dramaturgia pliniana e radriganeana. Os dois autores assumem a responsabilidade de colocar em questionamento "o passado não dito", fazendo de suas personagens objeto de questionamento do momento presente. Depois de estudar a obra dramática radriganeana, tive a oportunidade de compreender e aceitar a frase polêmica e recorrente do autor de que "a ditadura não acabou". Tal afirmativa permite que leiamos sua fala relacionando-a com as novas formas de inserção e legitimação do poder em nossa sociedade.

Com vistas a estabelecer uma leitura comparativa entre os textos dramáticos dos autores, distintos temas podem ser relacionados a partir de suas peças. A título de exemplo, posso citar, entre outros, a "estética do feio", as "instâncias do poder" o "existencialismo", "vozes na/da ditadura", "o uso da linguagem", "ecos da religiosidade", "a figura da mulher", "a temática social". Para esse ensaio, destaco, sinteticamente, as questões da "estética do feio", da presença temática do "existencialismo", da "linguagem" e do "poder".

Em Juan Radrigán e Plínio Marcos, o "feio" pode ser analisado como uma estética, por isso a nomenclatura de "a estética do feio" para se referir às obras dos dramaturgos. Nos seus textos, o vocábulo é mais que um adjetivo determinante, ou seja, o "feio" se transforma num signo de corrosão física, mas ao mesmo tempo social e ideológica, manifestando-se sob diferentes aspectos e, dessa forma, pode ser encontrado como indicação dos autores nas suas rubricas com vistas às futuras representações, definindo entre outros elementos constituintes da peça, vestuários, espaços físicos, adereços, etc.

A filosofia existencialista que postula a liberdade de eleição do homem como uma das premissas básicas se faz presente nas obras dos dramaturgos, principalmente nos textos radriganeanos. As problemáticas da existência individual são concretizadas na dramaturgia de Juan Radrigán e Plínio Marcos. Podemos, a partir de fala de Sartre 
(1984:6) de que "0 homem nada mais é do que aquilo que ele faz de si mesmo", observar a luta que o marginalizado trava para se inserir no sistema que se recusa a aceitá-10. Desse embate surgem pontos de fricção que nos remetem a temas recorrentes nos textos radriganeanos e plinianos como, entre outros, 0 medo/temor, o moral, a solidão, a angústia, a fome, a humilhação, a exploração, a perda da família, a incapacidade de amar, mas, sobretudo, a questão da liberdade de eleição, mesmo que essa escolha signifique a morte da personagem.

Nesse sentido, devo salientar que a obra dramática dos dois dramaturgos apresenta, também, vinculação com o teatro do absurdo. A construção dramática, o lugar destacado que outorga à ruptura da linguagem dialógica e a forte elaboração simbólica dos textos têm muito em comum com esse gênero dramático. Em Radrigán, por exemplo, a intenção sócio-existencial, assim como a incorporação da oralidade popular, o vincula aos precursores da estética do absurdo. 0 dramaturgo não sacraliza a palavra. Na sua obra, o absurdo é transcendido pelo sacrifício do "herói trágico popular", que reivindica a dignidade do ser humano. As personagens radriganeanas quando tomam consciência do "absurdo" da realidade a qual se encontram submetidas - e que desta realidade se desprendem temas como alienação, degradação, situação econômica e social deplorável, destruição da família e dos valores como a dignidade, honra, autenticidade - sentem-se desconformes com suas vidas, pois a elas (marginalizados, pobres, mendigos) tocou a pior parte da luta humana pela sobrevivência. Do enfrentamento com essa realidade inoperante, surge a angústia existencial e, com ela, a questão da liberdade, o questionamento da divindade e a esperança (ou falta dela).

Em se tratando da temática do uso da linguagem, ambos os dramaturgos nos fazem repensar a linguagem canônica na medida em que suas personagens marginalizadas trazem consigo suas próprias práticas discursivas, revelando uma fala que prima pelo uso da linguagem popular e não pelo emprego do discurso formal, cujo uso faria de suas personagens inverossímeis. Por isso que as gírias e os palavrões empregados não são gratuitos, uma vez que refletem o mundo em que as personagens vivem. As falas, ditos e expressões utilizados pelas personagens, sem sombra de dúvida, retratam aspectos geográficos, éticos e sociais. 


\section{EMTESE}

Belo Horizonte, v. 9, p. I-28I, dez. 2005

$\mathrm{Na}$ grande maioria das obras dos autores analisados, a questão do "poder" se converte num dos aspectos centrais da dramaturgia, fazendo com que possamos questionar a tipologia das classes sociais. A idéia de múltiplas explorações permite pensar a existência de localizações contraditórias de classe, que podem ser simultaneamente exploradas por um mecanismo e por outros. Neste sentido, observa-se que em cada texto o exercício do poder assume facetas diferenciadas, podendo ser lido como micro-poderes que se instalam. Como afirma Foucault (2003:XIV)

[...] nada está isento de poder. Qualquer luta é sempre resistência dentro da própria rede de poder, teia que se alastra por toda a sociedade e a que ninguém pode escapar: ele está sempre presente e esse exerce como uma multiplicidade de relações de forças. E como onde há poder há resistência, não existe propriamente o lugar da resistência, mas pontos móveis e transitórios que também se distribuem por toda a estrutura social.

Essa "multiplicidade de relações de forças" à qual se refere Foucault se faz presente nos textos. Berrão (personagem pliniana de Homens de papel, 1967), Giro e Osvaldo (personagens plinianas de O Abajur lilấs, 1969), Bereco (personagem pliniana de Oração para um pé-de-chinelo, 1969) e Miguel (personagem radriganeana de Hechos consumados, 1981) são, a título de exemplo, os representantes do que estou nomeando de micro-poderes, pois cada personagem é detentora de um poder - representado signicamente no ato de possuir uma arma, de ser dono de um quarto, de ter dinheiro, de ser o vigia de terras, respectivamente - e o exerce, inclusive, sob coerção de seus iguais. Por outro lado, temos outras manifestações de micro-poderes que se exercem de forma alegórica através da relação de possessão com determinados objetos: a balança de Berrão que pesa sempre para menos e em seu benefício; o abajur signo de discórdia, de medo, de repressão, de ruptura, de violação de direitos, da ditadura; a garrafa de cachaça símbolo de sobriedade para Rato (personagem pliniana de Oração para um pé-de-chinelo) e que representa, ao mesmo tempo, a possibilidade de esquecimento e de sublimação de sua memória; o porrete de Miguel que representa não só o instrumento de morte, mas a mão da ditadura. Através desses elementos simbólicos, quero demonstrar que "as relações de poder não se passam fundamentalmente nem ao nível do direito, nem da violência; nem são basicamente contratuais nem unicamente repressivas." (Machado apud Foucault, 2003: XV). 
Dessa forma, os textos dramáticos ao serem convertidos em montagens assumem e ganham outras relações, pois passam a dialogar com outras linguagens específicas do universo espetacular: luz, cenografia, figurino, adereços, sonoplastia, corpo, voz, ritmo, música, etc. Chamo atenção para esse aspecto pelo fato de que, na prática, o texto dramático é apenas um dos elementos que compõem o espetacular e são exatamente os outros elementos componentes da linguagem teatral que, em parceria com a obra literária, serão os responsáveis pelo resultado e sucesso da montagem.

Nesse sentido, propor, por exemplo, uma leitura espetacular de Fatos Consumados de Juan Radrigán é um exercício de contextualização e concretização da obra ao nosso momento enunciador. Nesta peça, Juan Radrigán verte, além das preocupações sociais, as preocupações existenciais de sujeitos que articulam suas angústias pessoais com uma linguagem que se resiste em caber dentro de um modelo valorativo acunhado na tradição intelectual ou na versão oficial do que se considera linguagem culta. Estamos diante de uma expressão discursiva que reproduz, ou melhor, que transcreve a sintaxe e léxico da linguagem oral própria do setor marginal chileno. As personagens expressam as profundas preocupações existenciais que as acossam mediante um discurso particular que, ao se transformar em objeto estético, através do texto dramático e de sua possível encenação, reclama um espaço e faz com que os sujeitos representados busquem a legitimação de suas presenças no espectro cultural do conglomerado social ao qual estão vinculados.

Acredito que os textos plinianos e radriganeanos ainda têm muito a dizer e, como Stuart Hall (2003: 377), considero que "a teoria é a atividade de teorizar, de continuar pensando, em vez do ponto final da produção de um modelo teórico último". A partir desta premissa e da constatação de que, no âmbito acadêmico, poucos estudos têm sido desenvolvidos sobre a obra dramática de Juan Radrigán e Plínio Marcos, é que vejo sentido em propostas de leituras teóricas e espetaculares sobre as peças desses dramaturgos, visto que suas personagens reapresentam o corpo reprimido do marginalizado e, ao mesmo tempo, reinventam a voz de um organismo social silenciado.

Eduardo Said (1996) argumenta que "o objetivo da atividade do intelectual é fazer progredir a liberdade e o conhecimento humanos". A meu 


\section{EM TESE}

Belo Horizonte, v. 9, p. I-28I, dez. 2005

ver, a obra dramática de Juan Radrigán e Plínio Marcos prima por apresentar esse objetivo e nos propicia (leitores e/ou espectadores) conhecer e entender melhor o universo cultural, os contextos históricos de sua produção e, ao mesmo tempo, as "pontes" que unem os dois países - Chile e Brasil -, pontes alegóricas que se concretizam nos âmbitos culturais, sociais, políticos e estéticos.

\section{ABSTRACT :}

This essay aims at carrying out a comparative study between the dramatic works of the Chilean playwright Juan Radrigan (1937) and the Brazilian playwright Plinio Marcos (1936/ 1999). The study aims at a better understanding of the particularities of Brazilian and Chilean political histories, since the two playwrights studied conceived great part of their dramatic works under the dictatorial period in their respective countries.

KEY WORDS: Juan Radrigán, Plínio Marcos, contexts, dramatic texts, spectacular texts.

\section{REFERÊNCIAS BIBLIOGRÁFICAS}

AVELAR, Idelber. Alegorias da derrota: a ficção pósditatorial e o trabalho do luto na América Latina. Trad. Saulo Gouveia. Belo Horizonte: Editora da UFMG, 2003.

BHABHA, Homi K. O local da cultura. Trad. Myriam Ávila; Eliana Lourenço de Lima Reis; Gláucia Renate Gonçalves. Belo Horizonte: Editora UFMG, 1998.

CONTRERAS, Javier Arancibia; MAIA, Fred; RIBEIRO, Vinícius. Plínio Marcos a crônica dos que não têm voz. São Paulo: Boitempo Editorial, 2002.

DE MARINIS, Marcos. Comprender el teatro - Lineamientos de una nueva teatrología. Buenos Aires: Editorial Calerna, 1997.

FOUCAUlt, Michel. Microfísica do poder. Org. e trad. Roberto Machado. 18. ed. Rio de Janeiro: Edições Graal, 2003.

HALL, Stuart. Da diāspora: identidades e mediações culturais. Liv Sovik (Org.). Trad. Adelaine La Guardia Resende et al. Belo Horizonte: Editora UFMG; Brasilia: Representação da UNESCO no Brasil, 2003.

MARCOS, Plínio. Barrela: peça em 1 ato. São Paulo: Global, 1976. 
- Homens de papel, Barrela. Garulhos: Parma, 1978. - O abajur lilás: peça em dois atos. São Paulo: Brasiliense, 1975. $\overline{\text { s.d.]. }}$.

- Oração para um pé-de-chinelo. Garulhos: Parma,

PAVIS, Patrice. A análise dos espetáculos. Trad. Sérgio Sálvia Coelho. São Paulo: Perspectiva, 2003.

RADRIGÁN, Juan. Hechos consumados - Teatro 11 obras. 2. Ed., Santiago: LOM Ediciones, 1993.

R0J0, Grínor. Muerte y resurrección del teatro chileno. Madrid: Ediciones Michay, S.A., 1973-1983.

SAID, Edward W. Representaciones del intelecutal. Barcelona: Ediciones Ibérica, S.A., 1996.

SARTRE, Jean-Paul. O Existencialismo é um Humanismo; A Imaginação; Questão de Método (0s pensadores). Seleção de Textos de José Américo Motta Pessanha. Trad. Rita Correia Guedes; Luiz Roberto Salinas Fortes; Bento Prado Júnior. São Paulo: Abril Cultural, 1984.

VILLEGAS, Juan. Ideología y discurso crítico sobre el teatro de España y América Latina. Minneapolis, Minnesota: The Prisma Institute, Inc., 1988. 